удК 331.5;3321244(100)

В. Г. Былков

Байкальский государственный университет, г. Иркутск, Российская Федерация

М. В. Самарина

Иркутский государственный университет путей сообщения, 2. Иркутск, Российская Федерация

\title{
ОСОБЕННОСТИ ФУНКЦИОНИРОВАНИЯ МИРОВОГО РЫНКА ТРУДА В УСЛОВИЯХ ЭКОНОМИЧЕСКОГО КРИЗИСА
}

\begin{abstract}
АНнОтАЦия. В условиях продолжающегося экономического кризиса происходит трансформация мирового рынка труда. В статье отражено влияние глобального экономического кризиса на мировой рынок труда. Определены тенденции изменения безработицы по отдельным странам мира. Приведена классификация отдельных групп стран по уровням социально-экономического развития и состояния рынка труда. Выявлены группы стран с низким уровнем безработицы. Проведена оценка уровня безработицы по развитым, развивающимся и слаборазвитым странам мира. Основное внимание в статье уделено анализу разных аспектов занятости на мировом рынке, где на сегодняшний день наблюдается увеличение численности безработных, дисбаланс и нестабильность экономической ситуации. Дана оценка социальной защищенности занятости в мире. Определено, что временная, случайная работа существенно снижает уровень социального обеспечения. Выявлены сектора экономики и страны, которые используют неформальные типы обеспечения занятости. Обозначены стратегические и практические рекомендации, разработанные МОТ и Всемирным банком, по реализации кризисных явлений на рынке труда. Определены траектории преодоления кризиса в сфере занятости населения на мировом рынке труда.

кЛючЕВЫЕ СЛОВА. Занятость; безработица; мировой рынок труда; миграция; глобализация; глобальный экономический кризис.

ИНФОРМАЦИЯ О СТАТЬЕ. Дата поступления 22 июня 2017 г.; дата принятия к печати 11 октября 2017 г.; дата онлайн-размещения 25 октября 2017 г.
\end{abstract}

\section{G. Bylkov \\ Baikal State University, Irkutsk, Russian Federation \\ M. V. Samarina \\ Irkutsk State Railway Transport Engineering University, \\ Irkutsk, Russian Federation}

\section{FEATURES OF GLOBAL LABOR MARKET FUNCTIONING IN TERMS OF ECONOMIC CRISIS}

ABSTRACT. In the context of the ongoing economic crisis, the global labor market keep transforming. The article reflects the impact of the global economic crisis on world labor market. It identifies the trends in unemployment changes in separate countries of the world. It brings forth a classification of separate groups of countries in terms of their socio-economic development levels and the labor market current state. It specifies groups of countries with a low unemployment level, makes an assessment of the unemployment level depending on developed, developing and undeveloped countries of the world. The article gives its major attention to analyzing various aspects of employment on the world market which currently registers an increase of the number of the unemployed, a misbalance and instability of the economic situation. It specifies that a temporary occasional job considerably decrease the social welfare level, identifies the sectors of economy and countries that use informal types of employment provision. The article marks the strategic and practical recommendations worked out by the ILO and the World Bank in terms of implementing crisis phenomena on the labor market. It determines the pathways of overcoming the crisis in the local employment sphere on the world labor market.

\section{Baikal Research Journal}


KEYWORDS. University; regional universities; lean manufacture; LEAN technologies; Quality Management System; entrepreneurship; strategies.

ARTICLE INFO. Received June 22, 2017; accepted October 11, 2017; available online October 25, 2017.

В эпоху глобализации, мировая экономика столкнулась с целой совокупностью ряда серьезных социально-экономических проблем. Это связано не только с высокой степенью неустойчивости экономического развития, высоким уровнем бифуркации демографических процессов, усиления миграционных потоков, но и нестабильностью экономического развития, явным дефицитом рабочих мест и нехваткой высококвалифицированной рабочей силы.

В настоящее время в мире формируются разнонаправленные тенденции, но реализация каждой из них существенно воздействует на изменение позиции людей и живого труда в социально-экономической сфере. В условиях глобализации эти тенденции, с разной силой проявляющиеся в зависимости от страны и региона, взаимодействуют, формируя мировые тенденции, которые воздействуют на развитие рынка труда дифференцируя уровень социально-экономического развития.

Как показывает опыт, социально-экономический кризис затронул большинство стран и регионов мира. Процесс развития рынка изучается многими исследователями, между тем изучение данных процессов носит фрагментарный или сугубо социально-демографический характер. В основе оценок воздействия кризиса на состояние рынка труда должны лежать критерии, которые характеризуют степень развития компонентов рынка труда. Поэтому еще в начале кризиса был определен набор социально-экономических индикаторов, которые характеризуют ситуацию на рынке труда [1]. Действительно, оценка и учет предлагаемых социально-экономических индикаторов может характеризовать состояние не только регионального, но и мирового рынка труда. Это связано с тем, что аналогичные тенденции можно отследить и на мировом уровне. Причем среди приоритетов следует выделить процессы глобализации, которые воздействуют на социально-экономическую ситуацию в мире в целом и сложившиеся тренды на мировом рынке труда. Весьма серьезной проблемой воздействие глобализации становиться в настоящее время, и они могут рассматриваться как продолжение экономического кризиса 2008 г. Как подчеркивают многие ученые, только те страны, которые сумеют адаптироваться к трансформациям в мировой экономике и могут решать целый комплекс социально-экономических проблем на рынке труда, смогут добиться серьезного прогресса в рамках повышения уровня жизни и укрепления социальной стабильности в обществе [2, с. 135].

Важнейшим индикатором, характеризующим изменения на рынке труда, является уровень безработицы. Несмотря на успехи многих развитых стран в преодолении безработицы в настоящее время уровень безработицы на мировом рынке труда продолжает увеличиваться. Можно выделить несколько групп стран по уровню безработицы. В первую группу включаются те страны, где на рынках труда наблюдается снижение числа безработных граждан (табл. 1).

Таблица 1

Уровень безработищы в \% к численности рабочей силы

\begin{tabular}{|l|r|r|r|r|r|}
\hline \multicolumn{1}{|c|}{ Страны } & \multicolumn{1}{|c|}{2013} & \multicolumn{1}{c|}{2014} & \multicolumn{1}{c|}{2015} & \multicolumn{1}{c|}{2016} & Март 2017 \\
\hline Россия & 5,5 & 5,2 & 5,6 & 5,5 & 5,4 \\
\hline Германия & 5,2 & 5,0 & 4,6 & 4,1 & 3,9 \\
\hline Италия & 12,1 & 12,7 & 11,9 & 11,7 & 11,7 \\
\hline Канада & 7,1 & 6,9 & 6,9 & 7,0 & 6,7 \\
\hline
\end{tabular}

\section{Baikal Research Journal}

электронный научный журнал Байкальского государственного университета 
Окончание табл. 1

\begin{tabular}{|l|r|r|r|r|r|}
\hline \multicolumn{1}{|c|}{ Страны } & \multicolumn{1}{|c|}{2013} & \multicolumn{1}{c|}{2014} & \multicolumn{1}{c|}{2015} & \multicolumn{1}{c|}{2016} & \multicolumn{1}{c|}{ Март 2017} \\
\hline Великобритания & 7,6 & 6,1 & 5,3 & 4,8 & 4,61 \\
\hline США & 7,4 & 6,2 & 5,3 & 4,9 & 4,5 \\
\hline Франция & 10,3 & 10,3 & 10,4 & 10,1 & 10,1 \\
\hline Япония & 4,0 & 3,6 & 3,4 & 3,1 & 2,8 \\
\hline 1) Февраль 2017 г. & & & & & \\
\hline
\end{tabular}

Источник: URL: http://www.gks.ru.

Наиболее яркий пример эффективной политики на рынке труда в условиях кризиса продемонстрировала Германия с низкими показателями безработицы. Следует отметить, что в стране имелось достаточно государственных средств, для частичной компенсации работодателям экономических потерь от сохранения занятости. В подавляющем же большинстве развитых экономик мира зависимость между падением производства и занятости было более очевидным, видимо, за счет того, что заработная плата составляет в издержках значительную величину и работодатели не могут позволить себе содержать лишних работников в условиях необходимости жесткого соблюдения трудового законодательства.

Несмотря на это, эксперты Международной организации труда (МОТ) в рамках продолжающегося кризиса на мировом рынке труда, прогнозировали, что в 2017 году работу будут искать более 3,5 млн человек и в дальнейшем количество безработных будет постепенно расти.

Эксперты МОТ к 2019 году прогнозируют, что количество безработных увеличится на 11 млн человек. Если сравнить, то в 2014 году в мире насчитывалось примерно 201 млн безработных, это на 31 млн больше, чем в 2008 году, когда только начался мировой экономический кризис.

Следующим индикатором, который характеризует качественные аспекты безработицы, является уровень долгосрочный уровень безработицы.

Даже в развитых экономиках по данным МOT часть безработных не работали год и более года (табл. 2). Серьезной проблемой длительной безработицы является не только существенное снижение получаемых доходов высвобожденных работников, но и деформация квалификационных характеристик рабочей силы. Опыт свидетельствует, что если на рынке будет наблюдаться длительная безработица то это может привести к потере работником квалификацию, и при этом профессиональные и трудовые навыки перестанут отвечать ожиданиям работодателей.

Часто подчеркивается, что в первую очередь оказалась наиболее уязвимой категорией в условиях глобального экономического кризиса- молодежь. Поэтому, среди атрибутов безработицы следует рассматривать уровень молодежной безработицы. Во всем мире на сегодняшний день 74,5 млн молодых людей в возрасте от 15 до 24 лет, это безработные. Это почти на 1 млн больше показателя, отмеченного годом раньше [3].

Уровень безработищы среди высокоразвитых стран мира, \%

Таблица 2

\begin{tabular}{|l|r|r|r|}
\hline Высокоразвитые страны & $\begin{array}{c}\text { Уровень } \\
\text { безработицы }\end{array}$ & $\begin{array}{c}\text { Долгосрочный уровень } \\
\text { безработицы }\end{array}$ & $\begin{array}{c}\text { Уровень безработицы } \\
\text { среди молодежи }\end{array}$ \\
\hline Норвегия & 3,5 & 0,7 & 9,2 \\
\hline Австралия & 5,2 & 1,1 & 12,2 \\
\hline Дания & 7,0 & 1,8 & 12,6 \\
\hline Швейцария & 4,4 & 1,3 & 8,5 \\
\hline Нидерланды & 6,7 & 2,4 & 11,0 \\
\hline
\end{tabular}

\section{Baikal Research Journal}


Окончание табл. 2

\begin{tabular}{|l|r|r|r|}
\hline \multicolumn{1}{|c|}{ Высокоразвитые страны } & \multicolumn{1}{|c|}{$\begin{array}{c}\text { Уровень } \\
\text { безработицы }\end{array}$} & $\begin{array}{c}\text { Долгосрочный уровень } \\
\text { безработицы }\end{array}$ & $\begin{array}{c}\text { Уровень безработицы } \\
\text { среди молодежи }\end{array}$ \\
\hline Канада & 7,2 & 0,9 & 13,5 \\
\hline Новая Зеландия & 6,9 & 0,7 & 15,8 \\
\hline
\end{tabular}

Источник: URL: http://www.ilo.org /moscow/news/wsws/3744115/long.ru/index.htm.

Даже в высокоразвитых странах уровень среди молодежи в достигла в 2015 г. более $13 \%$, (Канада, Новая Зеландия), что почти в три раза выше уровня безработицы среди безработиых взрослых. Показатель соотношения безработицы среди молодежи к безработице среди взрослых достиг своего исторического максимума. Молодежная безработица и ее уровень особенно высок в Северной Африке и на Ближнем Востоке, а также в ряде стран Латинской Америки. В развитых странах, а в частности в США и ЕС в 2015 году $35 \%$ молодежи, не могли работу найти более шести месяцев и больше. Особенно данная тенденция характерна для развивающихся стран (табл. 3).

Все это может весьма негативно сказаться на карьере молодежи, так как многие молодые люди на рынке труда находятся в условиях длительной безработицы в самом начале трудового пути и в ближайшее время, как показывает практика не предвидится положительных сдвигов. Если будет наблюдаться такая ситуация и дальше, когда молодежь будет месяцами искать работу, если будет увеличиваться ее отрыв от общества, то тогда государству очень дорого обойдется нежелание бороться с этой проблемой [4].

Таблица 3

Уровень безработицы среди отдельных развивающих стран мира, \%

\begin{tabular}{|l|r|r|r|}
\hline Развивающие страны & $\begin{array}{c}\text { Уровень } \\
\text { безработицы }\end{array}$ & $\begin{array}{c}\text { Долгосрочный уровень } \\
\text { безработицы }\end{array}$ & $\begin{array}{c}\text { Уровень безработицы } \\
\text { среди молодежи }\end{array}$ \\
\hline Румыния & 7,3 & 3,0 & 23,6 \\
\hline Уругвай & 6,4 & 7,1 & 19,2 \\
\hline Барбадос & 11,6 & 2,3 & 29,6 \\
\hline Болгария & 12,9 & 7,4 & 28,4 \\
\hline Малайзия & 3,0 & & 10,4 \\
\hline
\end{tabular}

Источник: URL: http://www.ilo.org /moscow/news/wsws/ 3744115/long.ru/index.htm.

Во всех других регионах мира- в Азии, Латинской Америке и странах Карибского бассейна и в Африке уровень занятости в кризисные годы практически не менялся, но производительность была выше зарплаты только в странах Азии. На Ближнем Востоке показатели занятости колебались, но падение ВВП и уровня производительности труда в любом случае были более значительными. Такая ситуация объясняется как невысоким уровнем оплаты труда, так и более гибкими трудовыми отношениями, позволяющими бизнесу экономить на найме работников [5].

Все качественные параметры безработицы (уровень совокупной, долгосрочной и молодежной безработицы) значительно критичны для подавляющего количества слаборазвитых стран (табл. 4).

Оценив состояние с безработицей на рынке труда специалисты отмечают, что более 61 млн человек потеряли работу с тех пор, как начался мировой экономический кризис, и дальнейшие прогнозирование ситуации на рынке показывает, что уровень безработицы будет увеличиваться до конца десятилетия. Это означает, что в течение продолжающегося кризиса рабочие места не будут увеличиваться и удовлетворять потребности экономики в целом [2].

\section{Baikal Research Journal}

электронный научный журнал Байкальского государственного университета 
Эксперты МOT прогнозировали, что в 2017 году работу будут искать еще 3 млн человек, а дальше число безработных будет увеличиваться в течение четырех лет ежегодно в среднем на 8 млн человек. Для того, чтобы решить эту проблему трудоустройства для такого большого числа безработных, необходимо будет создавать, как минимум 280 млн рабочих мест к 2020 году [2]. По прогнозам МОТ, численность безработных будет увеличиваться ежегодно в среднем на 6-8 млн человек, что приведет к серьезному дисбалансу на мировом рынке труда.

Уровень безработицы среди отдельных слаборазвитых стран мира

\begin{tabular}{|l|r|r|rr|}
\hline \multicolumn{1}{|c|}{ Страны } & $\begin{array}{c}\text { Уровень } \\
\text { безработицы }\end{array}$ & $\begin{array}{c}\text { Долгосрочный уровень } \\
\text { безработицы }\end{array}$ & $\begin{array}{c}\text { Уровень безработицы } \\
\text { среди молодежи }\end{array}$ \\
\hline Сербия & 22,1 & 18,7 & 49,4 \\
\hline Турция & 9,7 & 1,9 & 18,7 \\
\hline Шри-Ланка & 4,4 & 1,9 & 20,1 \\
\hline Иордания & 12,2 & 4,3 & 29,3 \\
\hline Албания & 13,4 & 11,4 & 30,2 \\
\hline Монголия & 7,9 & 3,4 & 16,5 \\
\hline Намибия & 29,6 & 30,9 & 56,2 \\
\hline
\end{tabular}

Источник: URL: http://www.gks.ru.

Среди важнейших функций государства для различных стран может выступать стремление к созданию новых рабочих мест, что способствует усилению роли правительств на международном рынке труда.

Это связано с тем, что именно активные меры обеспечения занятости способствуют преодолению острых социальных конфликтов в обществе, с которыми столкнулась существенная часть стран планеты. Как подчеркивают многие ученые, для большинства населения всех без исключения стран, трудовая деятельность является основным источником формирования доходов [4, с. 96]. Поэтому занятость населения рассматривается, как способ стабилизации не только экономической, но и политической ситуации в стране.

Продолжающаяся тенденция сокращения рабочих мест обусловлена различными социально-экономическими и структурными причинами. Примерно $74 \%$ глобального дефицита всех рабочих мест на рынке в 2015 г. вызвано уменьшением занятости женщин и молодежи, которые сейчас составляют около $42 \%$ от общей численности рабочей силы во всем мире.

Глобальная нехватка рабочих мест оказывает значительное влияние на совокупный объем заработной платы. По некоторым оценкам, потери заработной платы в мире составили 1412 трлн долларов США. Это соответствует примерно $1,3 \%$ всего ежегодного объема мирового производства и примерно $3 \%$ от всего мирового объема потребления.

Действительно, из-за глобального дефицита рабочих мест сокращается общий объем заработной платы в мире, также на замедление темпов роста серьезно влияет и совокупный объем заработной платы. Так к примеру, в странах Европейского Союза и в развитых экономиках медленные темпы роста заработной платы в посткризисный период и период кризиса привели в 2014 году к сокращению совокупного объема заработной платы в регионе на 497 млрд долларов США. Воздействие в целом таких факторов, как увеличение заработной платы, потребления и инвестиций, позволило бы сократить дефицит рабочих мест, за счет этого можно было бы увеличить глобальный ВВП приблизительно на 4 трлн долларов США [2].

\section{Baikal Research Journal}

электронный научный журнал Байкальского государственного университета 
Уровень занятости трудоспособного населения значительно отличается по странам и регионам от $41 \%$ в Ираке, $48 \%$ в Северной Африке, 60-65 \% в развитых странах, до более чем 70 \% в Китае и Бразилии и практически $80 \%$ в Исландии. Средний уровень занятости в мире снизился с $66 \%$ в 2007 до 64,7\% в 2011 году. К примеру, на мировом уровне увеличение занятости с 2011 года остановилось примерно на уровне 1,5 процента в год. В странах Европейского Союза и развитых экономиках рост занятости населения составил в среднем около $0,2 \%$ в год по сравнению с 1,1 \% с 2000 года по 2008 год. Такое снижение обусловлено ростом уровня безработицы в период мирового финансово-экономического кризиса.

Ситуация, сложившаяся в отдельных странах, во многом определяется как чисто институциональными особенностями регулирования рынка труда в той или иной стране, законодательство и коллективные соглашения, препятствующие массовым высвобождениям, так и структурой ее экономики и степенью ее включенности в мировое разделение труда. Положение осложняется тогда, когда наиболее уязвимые для кризиса отрасли, то есть отрасли, ориентированные на внешний спрос, являются одновременно наиболее трудоемкими. Именно в этих случаях падение объемов производства угрожает значительному числу занятых и вносит наиболее значительный «Вклад» в рост безработицы Важен и такой фактор, как диверсифицированность экономики и возможность ее переориентации с упавшего внешнего на внутренний спрос.

Как отмечалось, кризис означает увеличение неформальной занятости. Действительно, в настоящее время в мире трудятся более 3,5 млрд человек, однако характер их занятости очень различен. Примерно 1,75 млрд человек работают по найму и исправно получают по договору заработную плату. Более 1,7 млрд заняты в сельском хозяйстве, на каких-либо сезонных работах или же на созданных малых семейных предприятиях. При этом более 250 млн человек, среди которых преобладает молодежь, являются безработными и активно ищут работу. Около 2,5 млрд человек трудоспособного возраста не работают преобладающая часть из них это женщины, не ищут работу и мы не знаем, сколько из них хотели бы ее получить [3, с. 29].

В апреле 2016 года Международная организация труда (МОТ) опубликовала доклад «Перспективы занятости и социальной защиты в мире в 2016 году» ${ }^{1}$. В данном докладе было отмечено, что в странах, где работает более $85 \%$ всей мировой рабочей силы, $\mathrm{s}$ всех работников работают по временным или краткосрочным заключенным трудовым договорам, в условиях неформальной занятости населения. либо вообще без договора или они заняты семейным трудом который является неоплачиваемым.

В докладе МОТ было сказано, что стандартная форма занятости которая используется на мировом рынке оплачивается выше, чем другие формы занятости. Также было отмечено, что работники, которые заняты на условиях неполного рабочего дня, а также работники которые используются на временных работах, как правило, живут в бедности и социальной изоляции. Между тем на практика показывает, что большинству работников все труднее и труднее становится использовать стандартные модели занятости [6].

На сегодняшний день более $63 \%$ всех работников работают без каких-либо трудовых договоров. Основная часть работников на рынке труда являются в основном самозанятыми или могут выполнять работу в рамках домохозяйств в основном в развивающихся странах. Также следует отметить, что даже среди наемных работников менее половины (43\%) работают на основе заключения постоянных договоров. Даже

${ }^{1}$ URL: http: //www.ilo.org /moscow/news/wsws/ 3744115/long.ru/index.htm.

\section{Baikal Research Journal}

электронный научный журнал Байкальского государственного университета 
несмотря на рост числа работающих по найму, они составляют всего половину общей численности. Так, в развитых странах и в странах Юго-Восточной и Центральной Европы по найму трудятся примерно восемь из десяти работников, в то время в странах Африки и Южной Азии данный показатель примерно двое из десяти.

Работники которые работали на условиях неполного рабочего дня менее 30 часов в неделю в 86 странах, на их долю приходится около $65 \%$ всей глобальной занятости, что составляет более $17 \%$. Если рассматривать мировой рынок труда, то можно наблюдать рост занятости на условиях неполного рабочего дня, особенно среди молодежи и женщин. $К$ примеру, в условиях неполного рабочего дня доля женщин, занятых, составила примерно $24 \%$ по сравнению с $12,4 \%$ среди мужчин.

С одной стороны, конечно, в некоторых случаях нестандартные формы занятости населения могут помочь определенным слоям безработным выйти на рынок труда и найти работу. Хотя эти новые тенденции могут влиять и вызвать нестабильность рынка труда, которая затрагивает большинство работников на мировых рынках.

Существенной проблемой является увеличения объемов неформальной занятости, что связано со снижением масштабов социального обеспечения. Как свидетельствуют данные, системой пенсионного обеспечения сегодня в мире охвачены лишь $52 \%$ работников, тогда как среди самозанятых этот показатель составил только $16 \%$. Работники с постоянными трудовыми договорами примерно $80 \%$ выплачивают взносы в пенсионные фонды, а работники с временными трудовыми договорами всего $51 \%$. Количество незащищенных работников в правовом отношении с 2012 года увеличилось на 27 млн человек. Это проблема характерна для многих стран мира и от нее во всем мире страдают 1,44 млрд, основная их часть трудится в двух регионах, это Южная Азия и Африка.

Таким образом, наблюдаемый отход от традиционных трудовых отношений к более нестандартным видам занятости в основном связан с ростом неравенства в обществе и уровнем бедности во многих странах мира. Существенные изменения в социально-трудовой сфере могут привести к сокращению глобального спроса на труд и снижением темпов роста создания рабочих мест.

А вот Восточная Азия пытается решать эту проблему. Большая часть незащищенных занятых работников в регионе составляла в 2007 году 50,2 \%, а к 2020 году прогнозируется, что она должна снизиться до 38,9 процентов ${ }^{2}$.

В сложившейся ситуации, обеспечение занятости населения усугубляется снижением профессионально-квалификационных характеристик рабочей силы.

Так, как сегодня многие рабочие места требуют компетенций, которыми соискатели не владеют. В 2020 году по разным оценкам, мир столкнется с нехваткой квалифицированных работников, спрос на которых будет превышать предложение на рынке труда примерно на 40 млн человек. Эта нехватка очень остро будет касаться инженерно-технических специальностей, это создаст проблемы не только для предприятий, которые работают в сфере высоких технологий, но и для всей мировой экономики в целом. Также можно выделить и другие проблемы это экономия на труде высокооплачиваемых квалифицированных работников, полная или частичная их замена машинами, различными механизмами и устройствами, снижением спроса на неквалифицированный труд. Эту острую проблему на рынке труда нужно рассматривать только в рамках экономических и политических трансформаций, с которыми сталкивается и переживает современный мир [7, с. 113].

Рост численности трудовых мигрантов является одной из важнейших направлений развития мирового рынка труда. Ученые определяют воздействие международной миграции на рынок труда [8, с. 117].

${ }^{2}$ URL: http: //www.csr-ca.com/2017/03/13/perspektivyzaniatosti-i-socialnoi-zashity-v-mire-2017.

\section{Baikal Research Journal}

электронный научный журнал Байкальского государственного университета 
Положительно решить такую проблему перехода рабочей силы из одной страны в другую будет не возможно до тех пор, пока будет существовать так называемая «социальная ступенька» между государствами по уровню и качеству жизни населения. Практика свидетельствует, что в развитых странах Европы, США и Японии иностранные работники стали все чаще занимать вакансии высококвалифицированных специалистов. Эти страны уже сегодня столкнулись с дефицитом высококвалифицированных специалистов. Опытных специалистов все больше выходит на пенсию, а молодые специалисты не могут их полностью заменить на рынке труда [2].

Еще одна причина нехватки высококвалифицированных кадров в развитых странах мира кроется в сегодняшней политике правительства в сфере высшего образования. В Европе и США около 20 лет назад количество людей с высшим образованием превышало количество рабочих мест, которые для них создавались. Все это привело к сокращению инженерных специальностей и в связи с этим было принято решение закрыть несколько университетов в этих странах. Данные последствия вызовут серьезный дисбаланс на рынке труда и конкурентоспособность многих стран на мировом рынке труда будет подорвана.

Многим государствам и компаниям некоторых стран уже сейчас необходимо принимать серьезные меры, если эти страны хотят не допустить развитие серьезных последствий и деформации своих экономик.

В условиях кризиса мирового рынка труда особенно важно разрабатывать и осуществлять стратегические и практические меры по обеспечению занятости народонаселения.

В настоящее время специалисты Всемирного банка разработали программу практических действий по преодолению кризиса в сфере занятости, которая, по их мнению, должна внедряться поэтапно [5].

На первом этапе должны быть предусмотрены меры по обеспечению политического содержания обеспечения стабильного развития, включая макроэкономическую стабильность, формированию благоприятной деловой среды, привлечению инвестиций в развитие человеческого капитала. Именно данный этап предполагает формирование активной политики занятости, обеспечивающей создание и сохранение рабочих мест.

На втором этапе предполагается, что тщательно проработанная и продуманная политика в сфере труда позволит обеспечить на базе экономического роста повышение возможностей для трудоустройства, однако такого рода меры должны дополняться более конкретными мерами направленными на создание рабочих мест, который не ограничивался бы только рынком труда.

На третьем этапе национальные правительства в стратегическом плане должны определить, какие виды занятости способны внести наибольший вклад в ее социально-экономическое развитие, а также устранить препятствия, которые не позволяют организациям частного сектора создавать новые рабочие места.

Международные исследовательские и научные организации предлагают реализацию комплекса практических мер по выходу мирового рынка труда и занятости из зоны мирового кризиса.

Во-первых, это шаги, которые направлены на повышение объемов инвестиций в человеческий капитал и увеличение темпов роста создания рабочих мест, которые позволят преодолеть экономическую неопределенность. Для этого необходимо, особенно в развитых странах, разработать более эффективные, согласованные и реальные политические планы, разработать меры по увеличению доходов для того, что бы расширить и активизировать спрос, ускорить осуществление финансовых реформ с целью восстановления столь необходимой функции банковского

\section{Baikal Research Journal}

электронный научный журнал Байкальского государственного университета 
сектора, как поддержка кредитования для малых и средних предприятий и их инвестирования.

Во-вторых, предстоит реализация мер по координации и регулированию макроэкономической политики. Для этого необходимо повышать глобальный экономический спрос и активизировать создание новых рабочих мест на мировом рынке труда. Организационно-правовым, координационным структурным единицам, таким как G20 и Евросоюз, необходимо трансформировать свою политику на принципах взаимодействия на рынке труда. В большей мере следует согласовывать принимаемые политические меры для того, чтобы координированный глобальный рост и способствовать формированию его многополярных инструментов и механизмов. Наблюдающийся в настоящее время процесс роста покупательной способности среднего класса во многих развивающихся странах, является положительным моментом, который в будущем может стать важнейшим импульсом развития всей мировой экономики.

В-третьих, предстоит в ближайшее время преодолеть растущее различие профессиональных навыков работников потребностям развивающегося рынка труда. Поскольку кризис занятости труда - это по большей мере процесс циклический, потому следует готовиться к следующему циклу. Однако контролирующим органам необходимо решать углубляющие кризис структурные проблемы, таких как проблемы несоответствия навыков и профессий работников потребностям рынка труда. Поэтому правительствам многих стран следует более активно заниматься развитием профессиональных навыков и переподготовкой кадров, преодолевать тенденции роста безработицы. Также очень важны меры по возврату квалифицированных работников на рынок труда и консультирование всех работников по вопросам трудоустройства. Страны с развивающейся экономикой должны подталкивать структурные изменения в экономике, а там, где сельскохозяйственный сектор обеспечивает большое число рабочих мест, к примеру необходимо рекомендовать повышать производительность труда.

И наконец, в-четвертых, необходимо принять срочные и значительные меры по занятости молодежи, так как в настоящее время существует большой риск формирования «потерянного поколения».

Таким образом, последствия глобального экономического кризиса вызвали большие изменения мирового рынка труда, усилили его нестабильность и вызвали дисбаланс. Только практические исследования, позволят рассмотреть все аспекты и проблемы развития мирового рынка труда, помогут разработать действенные и эффективные меры по преодолению кризиса мирового рынка труда. Изучение всех процессов происходящих на мировом рынке труда даст возможность и российским исследователям лучше увидеть и понять перспективы функционирования и развития мирового рынка труда, для того чтобы создать эффективную модель российского рынка труда.

\section{Список использованной литературы}

1. Былков В. Г. Социально-экономические индикаторы предкризисной ситуации на региональном рынке труда [Электронный ресурс] / В. Г. Былков, М. В. Самарина // Известия Иркутской государственной экономической академии (Байкальский государственный университет экономики и права).— 2015- № 3.- Режим доступа: http://brj-bguep.ru/ reader/article.aspx $? \mathrm{id}=20144$.

2. Подвойский Г. Л. Мировой рынок труда: последствия глобализации и крисиза / Г. Л. Подвойский // Вестник финансового университета.— 2015. - № 4.- С. 132-138.

3. Щипанова Д. Г. Современный мировой рынок рабочей силы / Д. Г. Щипанова // МИР (модернизация, инновации, развитие). - 2013. - Вып. 15. - С. 26-30.

\section{Baikal Research Journal}


4. Бондарева Д. А. Мировой рынок труда / Д. А. Бондарева, И. А. Сорочайкин // Основы экономики, управления и права. - 2012. — № 2. - С. 92-98.

5. Рязанцев С. В. Мировой рынок труда и международная миграция / С. В. Рязанцев, М. Ф. Ткаченко. - М. : Экономика. 2010.- 303 с.

6. Смирных Л. И. Срочные трудовые договоры: влияние на движение рабочей силы и рабочих мест / Л. И. Смирных // Уровень жизни населения регионов России. - 2014. № 4. - С. 28-36.

7. Гаррифулина Н. Ю. Рынок труда рабочих профессий: российские и международные тенденции / Н. Ю. Гаррифулина, К. А. Мазаева // Экономика и экономические науки. 2014. - № 3. - С. 112-116.

8. Рывкина А. Н. Международная трудовая миграция, как фактор влияния на функционирование рынка квалифицированного труда в условиях глобализации / А. Н. Рывкина, Е. Г. Гущина // Известия ВолгГТУ. - 2012. - Вып. 13, № 7. - С. 113-119.

\section{References}

1. Bylkov V. G., Samarina M. V. Socio-economic indicators of pre-crisis situation on regional labor market. Izvestiya Irkutskoy gosudarstvennoy ekonomicheskoy akademii (Baikalskiy gosudarstvennyy universitet ekonomiki i prava) = Bulletin of Irkutsk State Academy of Economics (Baikal State University of Economics and Law), 2015, no. 3. Available at: http:// brj-bguep.ru/reader/article.aspx?id=20144. (In Russian).

2. Podvoiskii G. L. World labor market: consequences of globalization and crisis. Vestnik finansovogo universiteta $=$ Bulletin of Financial University, 2015, no. 4, pp. 132-138. (In Russian).

3. Shchipanova D. G. Modern world labor force market. MIR (modernizatsiya, innovatsii, razvitie) = MID (modernization, innovations, development), 2013, vol. 15, pp. 26-30. (In Russian).

4. Bondareva D. A., Sorochaikin I. A. World labor market. Osnovy ekonomiki, upravleniya $i$ prava = Basics of Economy, management and law, 2012, no. 2. pp. 92-98. (In Russian).

5. Ryazantsev S. V., Tkachenko M. F. Mirovoi rynok truda i mezhdunarodnaya migratsiya [World labor market and international migration]. Moscow, Ekonomika Publ., 2010, 303 p.

6. Smirnykh L. I. Term labor contracts: influence on movement of work force and jobs. Uroven' zhizni naseleniya regionov Rossii = Social standards of living of Russia's regions, 2014., no. 4, pp. 28-36. (In Russian).

7. Garrifulina N. Yu., Mazaeva K. A. Market of blue-collar occupation labor: Russian and international trends. Ekonomika i ekonomicheskie nauki = Economy and Economic Sciences, 2014, no. 3, pp. 112-116. (In Russian).

8. Ryvkina A. N., Gushchina E. G. International Labor migration as a factor of influence on functioning of qualified labor market in terms of globalization. Izvestiya Volgogradskogo gosudarstvennogo tekhnicheskogo universiteta = Bulletin of Volgograd State Technical University, 2012, vol. 13, no. 7, pp. 113-119. (In Russian).

\section{Информация об авторах}

Былков Владилир Георгиевич - доктор экономических наук, профессор, кафедра экономики труда и управления персоналом, Байкальский государственный университет, 664003, г. Иркутск, ул. Ленина 11, e-mail: bylkovVG@bgu.ru.

Саларина Мария Владилировна - кандидат экономических наук, доцент, Иркутский государственный университет путей сообщения 667057, г.Иркутск, ул. Чернышевского, 45, e-mail:samarina-mashenka@mail.ru.

\section{Authors}

Vladimir G. Bylkov - Doctor habil. in Economics, Professor, Chair of Labour Economy and Personnel Management, Baikal State University, 11 Lenin St., 664003, Irkutsk; e-mail: bylkovVG@bgu.ru.

Maria V. Samarina - PhD in Economics, Associate Professor, Irkutsk State Railway Engineering University, 45 Chernyshevsky St., 667057, Irkutsk; e-mail: samarina-mashenka@ mail.ru.

\section{Baikal Research Journal}




\section{Для цитирования}

Былков В. Г. Особенности функционирования мирового рынка труда в условиях экономического кризиса / Былков В. Г., Самарина М. В. // Baikal Research Journal. — 2017. T. 8, № 3. - DOI : 10.17150/2411-6262.2017.8(3).16.

\section{For Citation}

Bylkov V. G., Samarina M. V. Features of global labor market functioning in terms of economic crisis. Baikal Research Journal, 2017, vol. 8, no. 3. DOI: 10.17150/24116262.2017.8(3).16. (In Russian).

\section{Baikal Research Journal}

